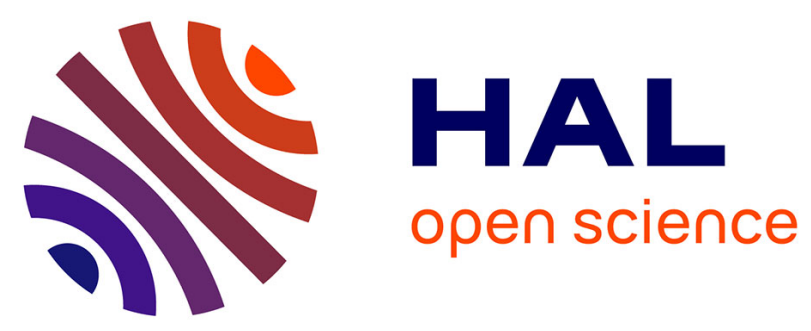

\title{
Natural history of allergic sensitization in infants with early-onset atopic 1 dermatitis: results from ORCA Study
}

\author{
Jocelyne Just, Emmanuelle Deslandes-Boutmy, Flore Amat, Kristell
}

Desseaux, Ariane Nemni, Emmanuelle Bourrat, Fatia Sahraoui, Isabelle

Pansé, Martine Bagot, Sébastien Fouéré

\section{To cite this version:}

Jocelyne Just, Emmanuelle Deslandes-Boutmy, Flore Amat, Kristell Desseaux, Ariane Nemni, et al.. Natural history of allergic sensitization in infants with early-onset atopic 1 dermatitis: results from ORCA Study. Pediatric Allergy and Immunology, 2014, 25, pp.668-673 10.1111/pai.12287 . hal01103219

\section{HAL Id: hal-01103219 \\ https://hal.sorbonne-universite.fr/hal-01103219}

Submitted on 14 Jan 2015

HAL is a multi-disciplinary open access archive for the deposit and dissemination of scientific research documents, whether they are published or not. The documents may come from teaching and research institutions in France or abroad, or from public or private research centers.
L'archive ouverte pluridisciplinaire HAL, est destinée au dépôt et à la diffusion de documents scientifiques de niveau recherche, publiés ou non, émanant des établissements d'enseignement et de recherche français ou étrangers, des laboratoires publics ou privés. 
1 Natural history of allergic sensitization in infants with early-onset atopic 2 dermatitis: results from ORCA Study

3 Jocelyne Just $\mathrm{MD} \mathrm{PhD}^{1,2,3}$, Emmanuelle Deslandes-Boutmy $\mathrm{PhD}^{4}$, Flore Amat

$4 \mathrm{MD}^{1,2,3}$, Kristell Desseaux $\mathrm{MSc}^{4}$, Ariane Nemni MD ${ }^{1}$, Emmanuelle Bourrat $\mathrm{MD}^{5}$, Fatia

5 Sahraoui $M D^{1}$, Isabelle Pansé $M D^{5}$, Martine Bagot $M D \mathrm{PhD}^{5}$, Sébastien Fouéré MD, $6 \mathrm{MSc}^{5}$.

$7 \quad{ }^{1}$ AP-HP-Service d'Allergologie Pédiatrique, Hôpital d'Enfants Armand-Trousseau,

8 Paris, France

92 INSERM, UMR S 1136, Institut Pierre Louis d'Epidémiologie et de Santé Publique, 10 Equipe EPAR, F-75013, Paris, France

11 3Sorbonne Universités, UPMC Univ Paris 06, UMR S 1136, Institut Pierre Louis

12 d'Epidémiologie et de Santé Publique, Equipe EPAR, F-75013, Paris, France

$13{ }^{4}$ Service de biostatistique et informatique médicale, Hôpital Saint-Louis, INSERM, U 14 717, Université Paris 7, F-75010, Paris, France.

15

${ }^{5}$ AP-HP- Service de Dermatologie, Hôpital Saint-Louis, Paris, France 17

18 Running title : biological outcomes of infants from ORCA Study

20 Address for correspondence

21 Pr. Jocelyne JUST

22 Service d'Allergologie Pédiatrique; Groupe Hospitalier Trousseau - La Roche 23 Guyon, 26, avenue du Docteur Arnold Netter, 75012 PARIS. FRANCE

24 Tel. +33144736317

25 Fax: +33144736635

26 E-mail: jocelyne.just@trs.aphp.fr 
Total word count: 2489. Tables: 2. Figures: 3

\section{ABSTRACT}

Just J, Deslandes-Boutmy E, Amat F, Desseaux K, Nemni A, Bourrat E, Sahraoui F, Pansé I, Bagot $M$, Fouéré $S$

\section{Natural history of allergic sensitization in infants with early-onset atopic dermatitis: results from ORCA Study}

\section{Pediatr Allergy Immunol}

BACKGROUND: Early-onset atopic dermatitis (AD) is a particular phenotype that may convey a risk of developing multiple sensitizations to allergens but little is known about the pathway of sensitization. The aims of this study were to describe the natural history of sensitization to allergens for this phenotype and to identify the most predictive marker associated with the risk of developing sensitization to inhaled allergens in a well-selected cohort of infants with AD. METHODS: Infants with active $A D$ were enrolled and prospectively explored for biological markers of atopy every year until the age of 6 years. Allergic sensitization was defined as the presence of positive specific IgEs to allergens and multiple sensitizations as being sensitized to $\geq 2$ allergens. Elevated blood eosinophilia was defined as an eosinophil blood count $\geq 470$ eosinophils $/ \mathrm{mm}^{3}$ and elevated total $\operatorname{lgE}$ as a serum $\mathrm{lgE}$ level $\geq 45 \mathrm{kU} / \mathrm{L}$. RESULTS: 229 infants were included. Elevated blood eosinophilia was observed at baseline in 60 children (26.2\%) and elevated total $\operatorname{lgE}$ in $85(37.1 \%)$. When elevated at baseline, eosinophilia and IgE levels remained significantly higher during the follow-up period. Sensitization to food allergens decreased from $58 \%$ to $34 \%$ whereas sensitization to inhaled allergens increased over time from $17 \%$ to $67 \%$. Initial multiple sensitizations to food allergens were the most predictive factor for the risk of developing sensitization to inhaled allergens at 6 years (OR 3.72 [1.68-8.30] $\mathrm{p}<0.001)$. CONCLUSIONS: In the early-onset AD phenotype, multiple sensitization 
56 to food allergens conveys a higher risk of sensitization to inhaled allergens than

57 single sensitization.

58 Key words Atopic dermatitis, sensitization, food allergens, inhaled allergens,

59 phenotypes, cohort

60

61

62

63

64

65

66

67

68

69

70

71

72

73

74

75

76

77

78

79

80

81

82

83

84

85

86

87

88 
90 Atopic dermatitis (AD), which often begins in infancy, is a chronic inflammatory disorder of the skin that affects 10 to $30 \%$ of children $\{1\}$. Prevalence of sensitization to inhaled allergens in the general population is between 16 to $25 \%$ [2]. It is suspected that there is a link between $A D$ and the occurrence of sensitization to inhaled allergens during childhood. This could be because of percutaneous entry of the allergens through an impaired skin barrier due to inflamation. Moreover, earlyonset $A D$, as well as the severity of $A D$, has been shown to be associated with a risk of sensitization to food allergens at 3 months of age [3]. Sensitization to food allergens in birth cohorts, particularly elevated egg-specific lgE, has also been shown to be a risk marker for sensitization to inhaled allergens later in life $\{4\}$. Furthermore, sensitization to inhaled allergens can predict the occurrence of respiratory disease which can start years before the first symptoms of allergic rhinitis or asthma [5]. All in all, AD could be the first step leading to asthma, particularly in children with severe [6] or early-onset AD [7]. However, the early-onset and severe phenotype of AD is quite rare; e.g., in Flohr et al.'s study $\{3\}$ conducted in 619 infants from a population of breastfed infants, only $3.6 \%$ had severe $A D$ and $5.4 \%$ were sensitized to at least one food allergen. This makes it relatively difficult to explore this phenotype. We therefore set out to explore a cohort of children suffering from early-onset $A D$ from the prospective longitudinal ORCA (Observatory of Respiratory risks linked with

109 Cutaneous Atopy) study to try to describe this phenotype more precisely. The 110 objectives of the present analysis were to describe the natural history of sensitization 111 in this cohort and then to identify the best marker associated with the risk of 112 developing sensitization to inhaled allergens.

\section{Methods}

\section{Design}

115 Patients were part of the ten-year (2002-2012) Observatory of Respiratory risks

116 linked with Cutaneous Atopy (ORCA) Study resulting from the collaboration between 117 two tertiary care centers, the Allergology Department at the Armand Trousseau 118 Children's Hospital and the Dermatology Department at the Saint-Louis Hospital, 
119 both in Paris, France. The study prospectively included children with AD referred to

120 the Saint-Louis Hospital by a primary care physician.

121 Ethics

122 Parents of each child provided written informed consent at inclusion. The protocol

123 was endorsed by the Institutional Review Board of the Medical Ethics Committee on

124 Research of the Saint-Louis Hospital. Data were collected for the study with respect

125 to the confidentiality of patient records.

126 Inclusion criteria We considered for inclusion all the children meeting the following

127 criteria: i. aged younger than 12 months, ii. with an active $A D$ diagnosed by a 128 dermatologist according to the United Kingdom Working Party criteria (UKWP) $\{8\}$

129 and ISAAC questionnaire $\{9\}$, iii. without a history of wheezing.

130 Data collection at inclusion

131 Clinical data collected were:

132 1. Gender

133 2. Active $A D$ defined by ISAAC questionnaire $\{9\}$ and $A D$ severity assessed by

134 the SCORAD questionnaire [10]. We defined a low severity group for children

135 when the SCORAD was under 15 , a medium severity group when the

136 SCORAD was between 15 and 40 , and a high severity group when the

137 SCORAD was above 40.

138 3. Any documented food allergy defined by relevant allergic symptoms following

139 consumption of a food allergen associated with a sensitization to the same

140 allergen.

141 Biological markers of atopy measured in peripheral blood included:

142 1. Specific IgEs for inhaled and food allergens (ImmunoCAP Phadiatop Infant;

143 Uppsala, Sweden). Sensitization was defined as a specific $\lg E$ concentration 
$\geq 0.35 \mathrm{kU} / \mathrm{L}$ in serum against one of the following inhaled and food allergens: house dust mite (HDM), cat and dog dander, pollens (birch tree, timothy grass, mugwort), cockroaches; cow's milk, hen's egg, peanut, soy, fish and wheat. Multiple sensitizations were defined as at least two positive specific lgEs to allergens.

2. Other biological markers such as blood eosinophilia (cell counting by automated Sysmex; France), and total IgE (measured by ImmunoCAP; Uppsala, Sweden). Thresholds were used to define increased levels: increased blood eosinophilia was defined as a concentration of 470 eosinophils $/ \mathrm{mm}^{3}$ or more and increased total $\mathrm{lgE}$ as a concentration of $45 \mathrm{kU} / \mathrm{L}$

\section{Prospective data collection}

156 Children were followed up on biological parameters at the age of 6 months and then

157 annually until the age of 6 years. Biological parameters assessed at each visit were: specific IgE levels against inhaled and food allergens; blood eosinophilia; and total $\lg E$ levels, as described above.

\section{Statistical analysis}

162 All the results were calculated from the export database. Statistical analysis was 163 performed using the Open Source $R$ software ( $>R$ 2.13.1) [R Development Core 164 Team (2009). R: A language and environment for statistical computing. R Foundation for Statistical Computing, Vienna, Austria. ISBN 3-900051-07-0, URL http://www.Rproject.org.]. Observed distributions of variables are described as numbers and 167 percentages for categorical variables and means, standard deviations and ranges for 168 continuous variables. The baseline characteristics of the patients were compared by 
169 the chi-square test or Fisher's exact test for categorical variables and Welsh's 170 student test for continuous variables. The variables defining severity of $A D$ were 171 discretized in three classes according to the SCORAD questionnaire as described 172 above. Clinical and biological features associated with the risk of developing 173 sensitization to inhaled allergens by the end of the follow-up period were calculated 174 with a logistic regression model. These prognostic factors $(p<0.2)$ were then included 175 in the multivariate analysis. Estimated OR are given with a 95\% Confidence Interval. 176 Survival analysis, describing time to sensitization (sensitization to inhaled allergens), 177 was performed by Kaplan-Meier analysis. For Kaplan-Meier analysis, we analysed 178 all clinical events by time to first event. 


\section{Results}

183 Three hundred children were initially considered for inclusion. Twenty-nine were 184 excluded ( 21 for lack of parental consent, 7 for a previous history of wheezing and 185 one for gluten intolerance). 42 were lost to follow-up immediately after the inclusion 186 visit and were not included in the analysis. The remaining 229 patients were included 187 for baseline characteristics analysis. 190 completed the last visit and formed the final 188 sample. The baseline characteristics of the children who were not included in the 189 final analysis did not differ from those of the final sample (data not shown). Figure 1 190 summarizes the patients flowchart.

\section{Descriptive data at baseline}

192 Clinical parameters. There were 134 boys (58.5\%) and the mean age was $6.5 \pm 2.7$ 193 months (mean $\pm S D$ ). Mean SCORAD was $34.2 \pm 21.0$ (mean $\pm S D$ ). Food allergy was 194 present in $6 \%(13 / 229)$ of the children. 173 children $(75.6 \%)$ had a parental history of 195 atopy.

\section{Biological markers}

197 Blood eosinophilia. Increased levels of blood eosinophilia were observed in $26.2 \%$ 198 (59/225) with an average value of $356.2 \pm 548.7 / \mathrm{mm}^{3}$ (mean \pm SD).

199 Total IgE. Increased total IgE was observed in $36.9 \%(83 / 225)$ with an average 200 value of $111.2 \pm 316.1 \mathrm{KU} / \mathrm{L}$ (mean $\pm S D$ ).

201 Specific IgE. 58\% (132/229) of the children had sensitization to food allergens and $20237 \%$ (86/229) multiple sensitizations. Hen's egg, cow's milk, peanut represented $20395 \%$ (125/132) of sensitization to food allergens (hen's egg $44 \%$, cow's milk $26 \%$, 204 peanut $25 \%$, fish $4 \%$, wheat $3 \%$, soy $2.2 \%)$. Seventeen percent $(40 / 229)$ of the 205 children were sensitized to at least one inhaled allergen. Cat dander represented 
$20652 \%(21 / 40)$ of sensitization to inhaled allergens, HDM and dog dander $17 \%(7 / 40)$,

207 all the pollens $12 \%(5 / 40)$ and cockroaches $2.5 \%(1 / 40)$.

208 Descriptive atopic biological markers during the follow-up period

209 Changes in blood eosinophilia. Analysis by a linear mixed model taking the level of

210 blood eosinophilia at baseline variable as an interaction with time showed that levels

211 of eosinophilia remained on average significantly higher in children with an increased

212 level of blood eosinophilia at baseline, compared to those with a low level at baseline

$213\left(+705 / \mathrm{mm}^{3}\right.$ vs $+76.1 / \mathrm{mm}^{3}$ over the follow-up period, respectively, $\left.\mathrm{p}<0.001\right)$.

214 Changes in total IgE. Analysis based on a linear mixed model of the total IgE level 215 variable considered as an interaction with time showed that children with an 216 increased total $\operatorname{lgE}$ at baseline had significantly higher average values throughout 217 follow-up than the children in whom the initial total lgE value was normal $(+284.6$ $218 \mathrm{kU} / \mathrm{L}$ vs $+39.2 \mathrm{kU} / \mathrm{L}$ over the follow-up period, $\mathrm{p}<0.001$ ) (Figure 2).

219 Changes in specific lgEs.

220 Overall, sensitization to food allergens decreased from $58 \%$ (132/229) at inclusion to $22134 \%(66 / 195)$ at the end of the follow-up period. In contrast, the percentage of 222 children sensitized to inhaled allergens increased over time from 17\% (39/229) at 223 inclusion to $67 \%(130 / 195)$ at the end of follow up. $46 \%(90 / 195)$ of the children were 224 sensitized to both food and inhaled allergens at the end of the follow-up compared to $22517 \%(39 / 229)$ at baseline. More precisely, at the end of the follow-up period 226 sensitization to inhaled allergens consisted of timothy grass pollens $(30 \%)$, HDM $227(28 \%)$ while sensitization to cat dander decreased to $18 \%$. Sensitization to dog 228 dander remained stable at around $5 \%$, as well as birch pollen that represented $18 \%$ 229 of sensitizations. Hen's egg, cow's milk and peanut together represented $86 \%$ of 
230 sensitizations to food allergens, with $35 \%, 29 \%$ and $22 \%$ for peanut, egg and cow's

231 milk respectively (Figure 3).

232

233 Factors associated with the risk of sensitization to inhaled allergens at the end 234 of the follow-up period

235 In univariate analysis, clinical and biological markers were evaluated as risk factors 236 for developing inhaled sensitization (Table 1). No clinical parameters (such as 237 severity of atopic dermatitis or food allergy) were found to be risk factors. In contrast, 238 elevated total $\lg \mathrm{E}$ at baseline emerged as a risk factor for developing sensitization to 239 inhaled allergens at the end of follow up (OR $2.94\{1.58-5.47\} \quad p<0.001)$. One 240 hundred infants $(76.9 \%)$ sensitized to food allergens were sensitized to inhaled 241 allergens at 6 years (OR $3.32\{1.90-5.84\} \quad p<0.001)$. More precisely, infants with 242 multiple sensitizations to food allergens were more likely to be sensitized to inhaled 243 allergens (OR $4.32\{2.22-8.40\} p<0.001$ ) than infants with a single food sensitization 244 (OR $2.20\{1.05-4.60\} \mathrm{p}=0.035)$.

245 In multivariate analysis, only sensitization to food allergen remained a determinant 246 and multiple food sensitizations were the most predicitve marker associated with the 247 risk of developing sensitization to inhaled allergens at shool age (OR $3.72\{1.68-8.30\}$ $248 \mathrm{p}<0.001)$. This was almost double than that for children with one food sensitization 249 (OR $2.20\{1.01-4.72\} \mathrm{p}=0.05)$ (Table 2). 


\section{Discussion}

257 The main result of this study is that multiple sensitizations to food allergens as 258 opposed to a single sensitization, could be a predictor of sensitization to inhaled 259 allergens in children suffering from early-onset AD. This finding leads to the 260 emergence of a particular phenotype of sensitizations in early-onset AD.

262 High T-helper cell 2 (Th2) dominant lymphocyte pattern exists in early-life and persists during preschool age

264 We have shown that both elevated blood eosinophilia and elevated total IgE seem to 265 follow a track during childhood for infants with a particular phenotype of AD. This 266 corresponds to what is known as the extrinsic form of $A D$ as opposed to the intrinsic 267 form. While both forms are clinically identical, the former is characterized by high 268 levels of specific IgEs. Yamamoto et al. $\{12\}$ reported significant differences in terms 269 of heterogeneity of the interleukin 5 gene between $A D$ with high and low blood 270 eosinophil levels. Thus AD can present different clinical phenotypes-genotypes. 271 There is considerable evidence that some individuals with AD present immune 272 dysregulation, including increased serum $\operatorname{IgE}$ and allergen sensitization, and 273 increased Th2 cytokine expression in eczematous lesions $\{13\}$. Genetic factors 274 predispose atopic subjects to mount exaggerated Th2 responses $\{14\}$ and to 275 exaggerated abnormality of the epidermal barrier $\{15\}$, which may favor allergic 276 sensitization. Recently, Suárez-Fariñas et al. $\{16\}$ demonstrated a significant 277 correlation between IgE levels and SCORAD scores $\left(r=0.76, p<10^{-5}\right)$ only in patients 278 with extrinsic AD. 
Sensitizations to food allergens move towards sensitizations to inhaled

281 allergens in some children suffering from early-onset $A D$ Extrinsic AD implies

282 the presence of a Th2 lymphocyte pattern with a cytokine profile facilitating an $\lg E$

283 response to environmental antigens. It is therefore hardly surprising that early 284 expression of $\mathrm{lgE}$-mediated sensitization to food is accompanied by a high risk of 285 sensitization to inhaled allergens. This fact is in accordance to results published from 286 the DARC cohort, in which predominately sensitization to foods, however shifting 287 toward inhalant allergens with age ( Eller E, Kjaer HF, Høst A, Andersen KE, 288 Bindslev-Jensen C.Development of atopic dermatitis in the DARC birth cohort. 289 Pediatr Allergy Immunol. 2010 Mar;21(2 Pt 1):307-14.)

290 In the case of early-onset eczema, IgE sensitization often occurs weeks or months 291 after the eczema lesions first appear, suggesting the allergens are first introduced 292 through the skin. Once allergens have penetrated the skin barrier, they interface with 293 antigen-presenting cells, which can then initiate a Th2 response by dendritic cells $294\{17\}$. The ensuing cascade can result in a long-lasting response with sensitization of 295 the host. Subsequent exposures can then lead to allergic rhinitis and asthma $\{18\}$.

296 A recent larger birth cohort study demonstrated a strong association between food 297 allergen sensitization, especially hen's egg, and asthma development by age 6 years $298\{19\}$. Our study therefore confirms that early-onset $A D$ is often associated with 299 sensitization to food allergens and more precisely multiple food sensitizations.

300

301 Multiple food sensitizations are the most predictive biomarker of early 302 sensitization to inhaled allergens

303 These results validate our previous findings that there are multiple atopic phenotypes $304\{20\}$. In the same way, Lazic et al. $\{21\}$ recently validated his previous study 
305 suggesting that allergic phenotypes change little over time, and that one phenotype with sensitization to a wide variety of allergens was much more likely to give rise to 307 asthma during childhood. This class is relatively unfrequent, comprising 308 approximately one third of the children who would be considered atopic by 309 conventional criteria. In the same manner, in a particular phenotype with early-onset $310 \mathrm{AD}$, we have shown here that sensitization to food allergens conveys a high risk of 311 sensitization to inhaled allergens rather when multiple than when unique. This finding 312 supports the hypothesis that the clinical expression of allergic diseases does not 313 merely depend on the presence of specific $\lg E$ antibodies, but rather on patterns of $314 \lg$ E responses over time.

Strength and limitations of our study

317 The strength of the study resides in the fact that it was a longitudinal prospective 318 cohort in a highly selected population of infants with early-onset AD explored 319 annually in a standardized manner. However, one limitation could be the rather small 320 size of the cohort and the absence of a control group. However, as mentioned in the 321 introduction, we selected a rare but potentially severe phenotype i.e., early-onset AD. 322 In this context, the size of this selected population was greater than the number of 323 patients suffering from this phenotype if selected from a large birth cohort. It would 324 have been of interest to know if multiple food sensitizations could predict not only 325 sensitization to inhaled allergens but also to severe allergic diseases such as 326 persistent $A D$ and mainly asthma. Nevertheless, inhaled sensitization has been 327 found to be a strong predictor of asthma development and airway 328 hyperresponsiveness up to school age, which is a strong risk factor for respiratory 329 allergies \{22. In the same manner, Kjaer HF et al showed that children with atopic 
330 dermatitis, asthma, or rhinoconjunctivitis, and sensitization at $6 \mathrm{yr}$, were sensitized to 331 food allergens to a large extent $(53 \%, 42 \%$, and $47 \%$, respectively) already at 6 332 months. This relationship will constitute our future research on this cohort.

333

334 In conclusion, Our data have showed longitudinal changes in sensitization patterns 335 of children with early-onset $A D$ and more precisely that multiple food sensitizations, 336 rather than single food sensitization, conveys a high risk of sensitization to inhaled 337 allergens at school age. It is thus important to identify this phenotype during infancy 338 to optimize patient management.

\section{Acknowledgements}

340 Grants for this study were received from Merck Sharp Dohme. 
342 Figure 1. Flow-chart of the study.

343 Legend: AD atopic dermatitis, n number of patients, mean age at each visit is under brackets. 


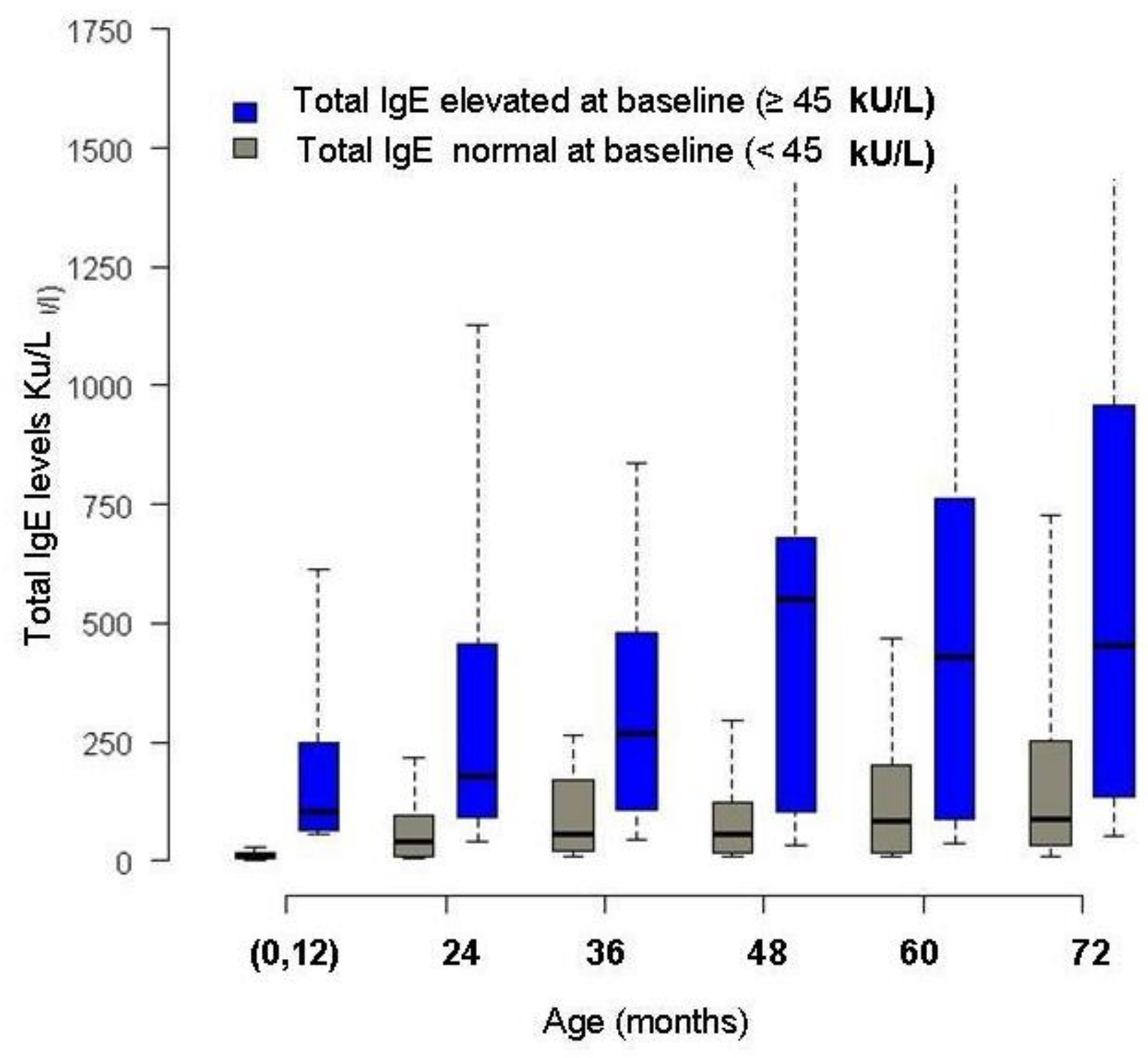


345 Figure 2: Phenotypes of total lgE levels during the 72 months of follow up: changes in the low (<45 kU/L) and high ( $\geq 45$

$346 \mathrm{kU} / \mathrm{L}$ ) total $\mathbf{l g} \mathrm{E}$ levels at inclusion. The horizontal lines of the box represent the lower, median and upper quartile, the hatched 347 traits represent the values outside of the whiskers (the ends of the whiskers represent the lowest datum still within 1.5 interquartile 348 range (IQR) of the lower quartile, and the highest datum still within 1.5 IQR of the upper quartile). 
A

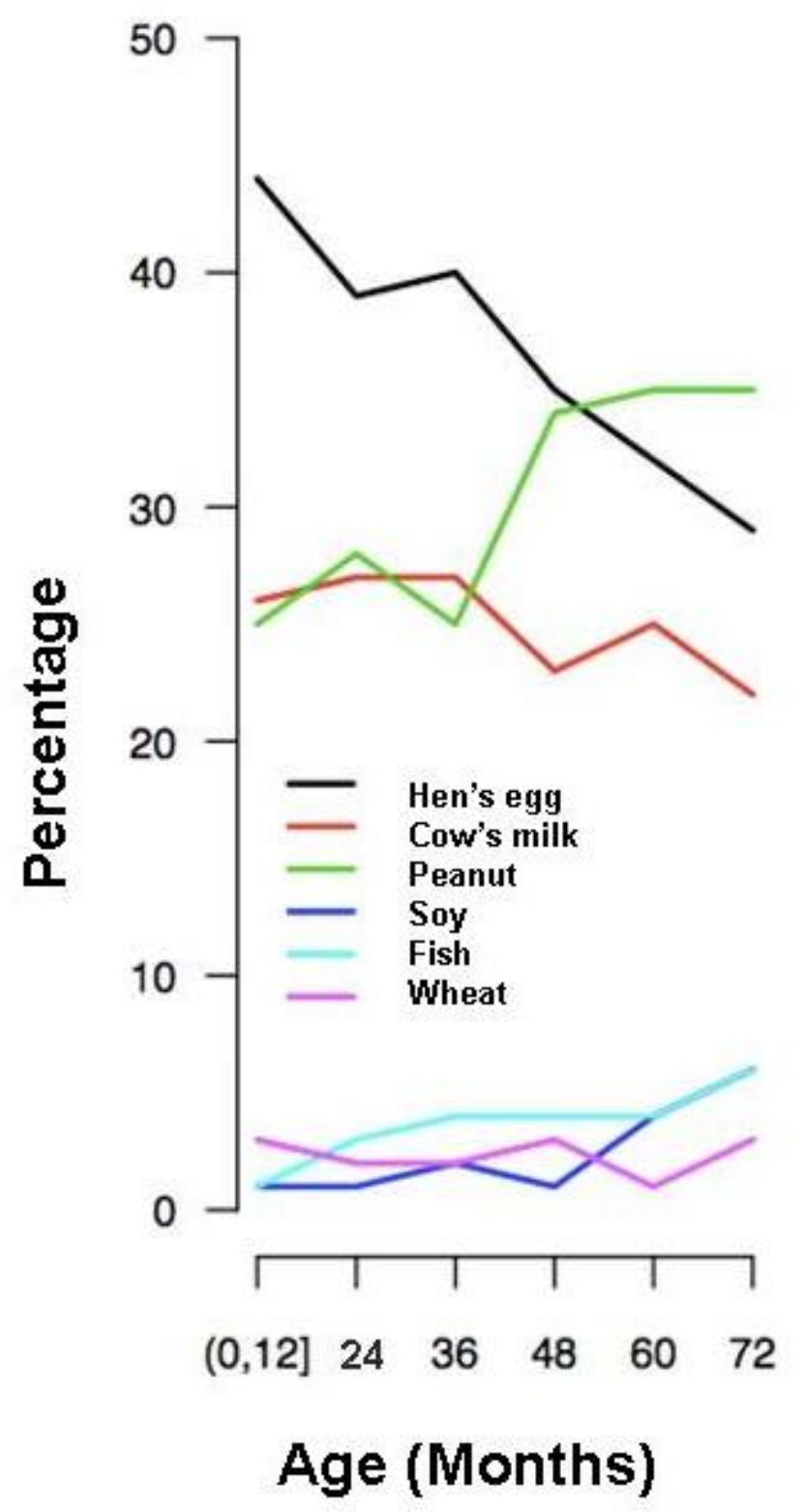

B

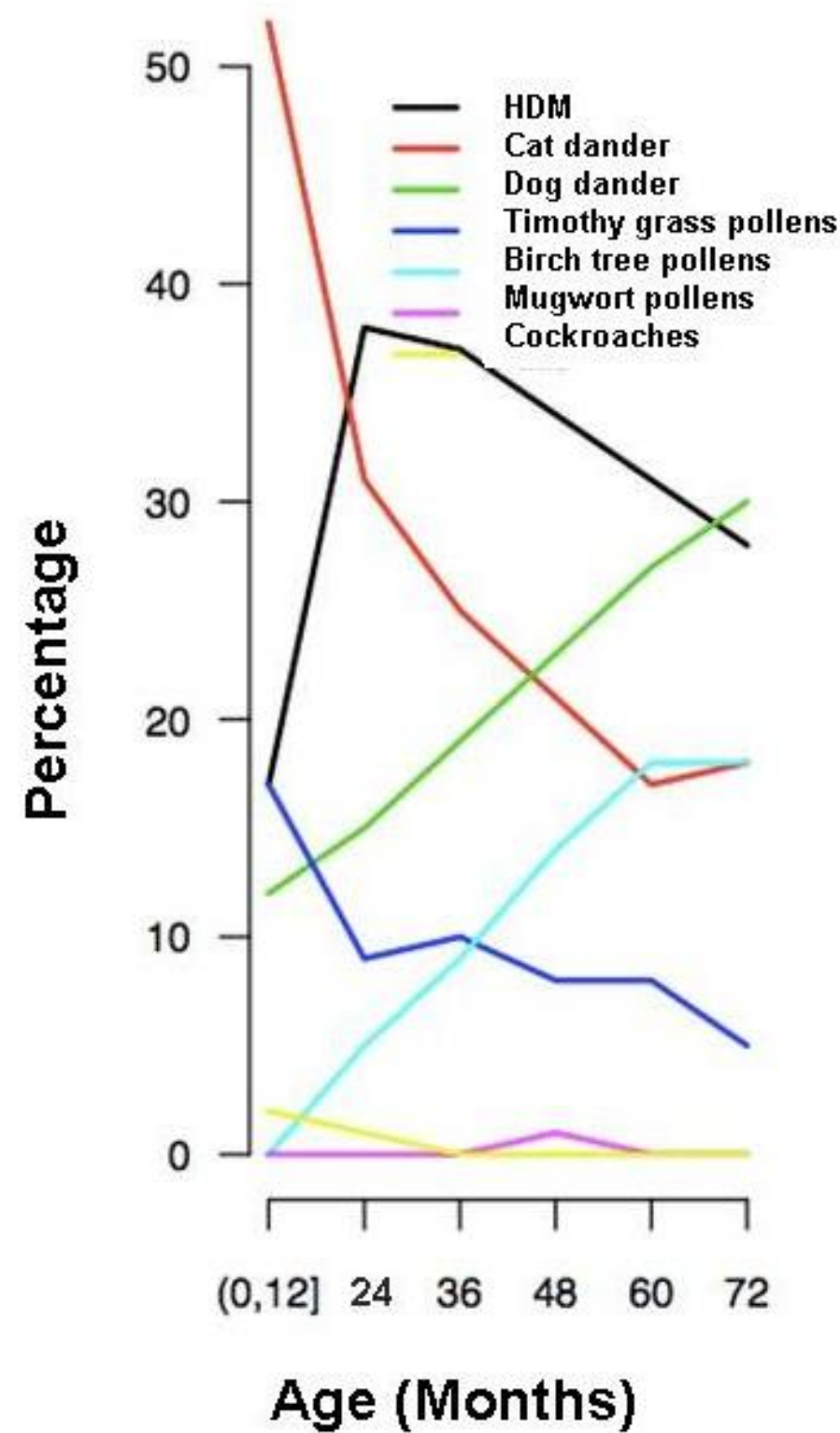


350 Figure 3: Changes in each sensitization to food (A) and inhaled allergen (B) during the 72 months of the follow-up

351 Changes are expressed in percentage of sensitized children. HDM house dust mite 


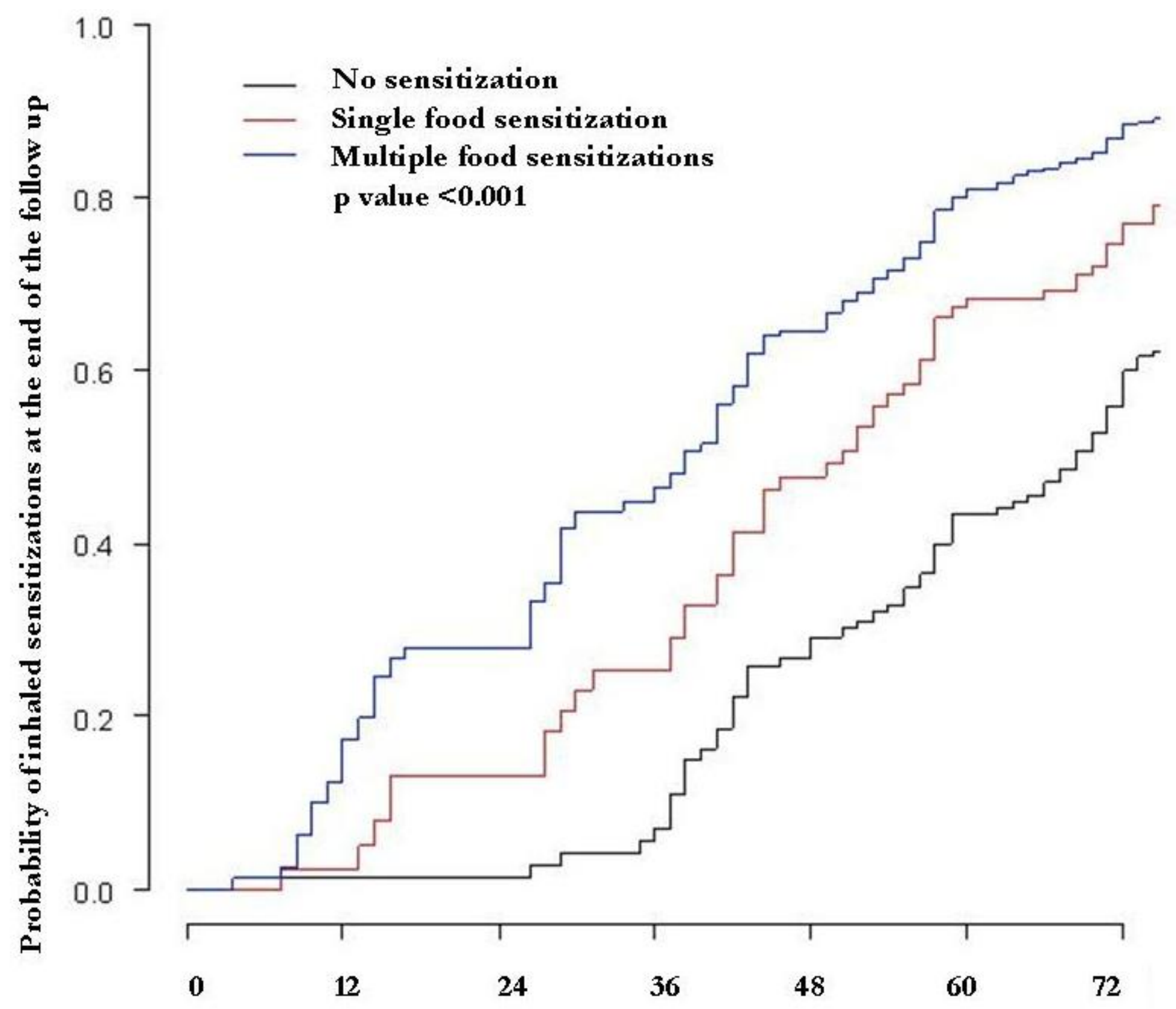


Table 1: Estimated univariate OR of variables at baseline associated to sensitization to inhaled allergens at the end of

Sensitization to inhaled OR $(\mathrm{Cl} 95 \%)$ p-value

allergens at 5 or 6 years $\mathrm{N} / \mathrm{N}$

total

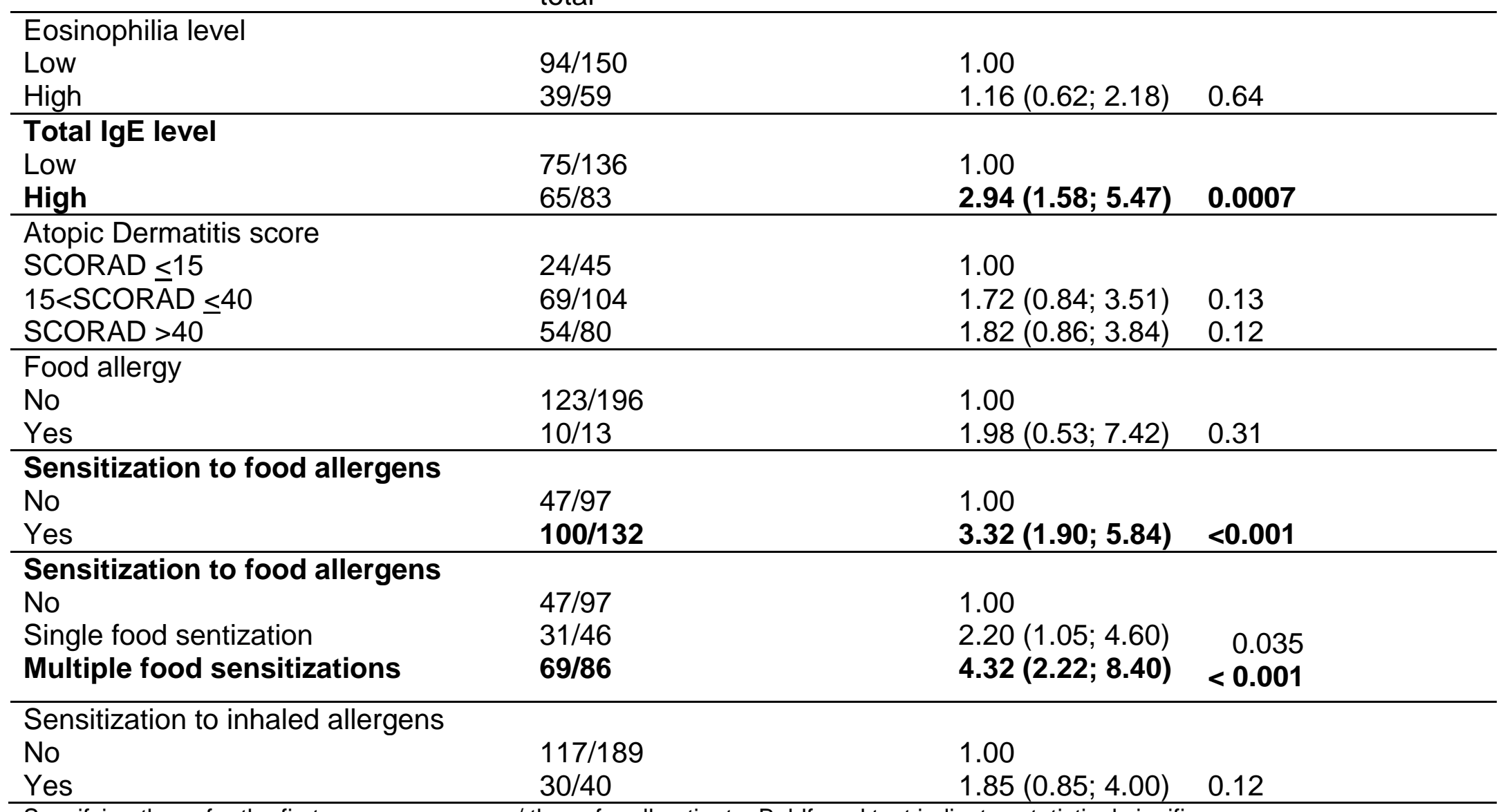

356 Specifying those for the first group awareness / those for all patients. Boldfaced text indicates statistical significance.

357 Allergen sensitization: specific $\lg \mathrm{E} \geq 0.35 \mathrm{kU} / \mathrm{L}$. multiple senstizations to food allergen is defined as two or more specific allergen sensitizations. 
Table 2: Estimated multivariate OR of variables at baseline associated to sensitization to inhaled allergens at the end of follow up

\begin{tabular}{lll}
\hline Covariables at baseline & Multivariate models & \\
\hline & OR $(\mathrm{Cl} 95 \%)$ & p-value \\
\hline Total lgE level & 1.00 & 0.27 \\
Low & $1.52(0.72 ; 3.21)$ & \\
High & & \\
\hline Sensitization to food allergens & 1.00 & \\
No & $\mathbf{2 . 2 0 ( 1 . 0 1 ; ~ 4 . 7 2 )}$ & $\mathbf{0 . 0 5}$ \\
Single food sensitization & $\mathbf{3 . 7 2 ( 1 . 6 8 ; 8 . 3 0 )}$ & $\mathbf{0 . 0 0 1 2}$ \\
Multiple food sensitizations & & \\
\hline
\end{tabular}

Allergen sensitization: specific $\lg E \geq 0.35 \mathrm{kU} / \mathrm{L}$. Multiple senstization to food allergen is defined as sensitization to two or more specific allergens. Risk factors associated with allergic sensitization to inhaled allergens in the univariate analysis $(p<0.2)$ are included in the multivariate analysis. Boldface values indicate statistical significance. 


\section{References}

371 1. Williams $\mathrm{H}$, Stewart A, von Mutius E, Cookson W and Anderson HR. Is eczema

372 really on the increase worldwide? J Allergy Clin Immunol 2008; 121:947-54.

373 2. Migueres $M$, Davila I, Frati $F$, Azpeita $A$, Jeanpetit $Y$, Lhéritier-Barrand $M$, et al.

374 Types of sensitization to aeroallergens: definitions, prevalences and impact on the

375 diagnosis and treatment of allergic respiratory disease. Clin Tr Allergy 2014; 4:16

376 3. Flohr C, Perkin M, Logan K, Marrs T, Radulovic S, Campbell LA, et al. Atopic

377 dermatitis and disease severity are the main risk factors for food sensitization in

378 exclusively breastfed infants. J Invest Dermatol 2014; 134:345-50

379 4. Asarnoj A, Ostblom E, Kull I, Lilja G, Pershagen G, Hedin G, et al. Sensitization to 380 inhalant allergens between 4 and 8 years of age is a dynamic process: results friom 381 the BAMSE birth cohort. Clin Exp Allergy 2008; 38: 1507-1513

382 5. Hatzler L, Panetta V, Lau S, Wagner P, Bergmann R, Illi S, et al. Molecular 383 spreading and predictive value of preclinical IgE response to Phleum pretense in 384 children with hay fever. J Allergy Clin Immunol 2012: 130; 894-901

385 6. Silverberg J, Simpson EL. Association between severe eczema in children and 386 multiple comorbid conditions and increased healthcare utilization. Pediatr Allergy 387 Immunol 2013; 24: 476-86

388 7. Carlsten C, Dimich-Ward H, Ferguson A, Watson W, Rousseau R, Dybuncio A, et 389 al. Atopic dermatitis in a high-risk cohort: natural history, associated allergic 390 outcomes, and risk factors. Ann Allergy Asthma Immunol 2013; 110:24-8 391 8. Williams HC, Burney PG, Pembroke AC, Hay RJ. Validation of the UK diagnostic 392 criteria for atopic dermatitis in a population setting. UK Diagnostic for Atopic 393 Dermatitis Working Party. Br J Dermatol 1996; 135: 12-17

394 9.Asher MI, Montefort S, Bjorksten B, Lai CK, Strachan DP, Weiland SK, et al.

395 Worldwide time trends in the prevalence of symptoms of asthma, allergic 396 rhinoconjunctivitis, and eczema in childhood: ISAAC Phase One and Three repeat 397 multicountry cross-sectional surveys. Lancet 2006; 368 (9537): 733-43.

398 10. Gelmetti C, Colonna C. The value of SCORAD and beyond. Towards a 399 standardized evaluation of severity? Allergy 2004; 59: 61-65

400 11. Just J, Nicoloyanis N, Chauvin M, Pribil C, Grimfeld A, Duru G. Lack of 401 eosinophilia can predict remission in wheezy infants? Clin Exp Allergy 2008; 38: 767$402 \quad 73$ 
12. Yamamoto $\mathrm{N}$, Sugiura $\mathrm{H}$, Tanaka $\mathrm{K}$, Uehara M. Heterogeneity of interleukin 5

404 genetic background in atopic dermatitis patients: significant difference between those with blood eosinophilia and normal eosinophil levels, J Dermatol Sci 2003; 33:121-6 13. Brown S and Reynolds NJ, Atopic and non-atopic eczema. BMJ 2006; 332:584-8. 14. Haagerup A, Bjerke T, Schiotz PO, Dahl R, Binderup HG, Tan Q et al. Atopic dermatitis—a total genome-scan for susceptibility genes. Acta Derm Venereol 2004; 84:346-52.

410 15. Cork MJ, Danby SG, Vasilopoulos Y, Hadgraft J, Lane ME, Moustafa M et al.

411 Epidermal barrier dysfunction in atopic dermatitis. J Invest Dermatol 2009; 129:8924121908.

413 16.Suárez-Fariñas M, Dhingra N, Gittler J, Shemer A, Cardinale I, de Guzman Strong 414 C et al. Intrinsic atopic dermatitis shows similar TH2 and higher TH17 immune 415 activation compared with extrinsic atopic dermatitis. J Allergy Clin Immunol. 2013; 416 132:361-70.

417 17. Nemoto-Hasebe I, Akiyama M, Nomura T, Sandilands A, McLean WH, Shimizu

$418 \mathrm{H}$. Clinical severity correlates with impaired barrier in filaggrin-related eczema. J 419 Invest Dermatol 2009; 129:682-9.

420 18. Hudson TJ. Skin barrier function and allergic risk, Nat Genet 2006; 38:399-400.

421 19. Bekkers MB, Aalberse RC, Gehring U, Kerkhof M, Koppelman GH, de Jongste $422 \mathrm{JC}$ et al. Hen's egg, not cow's milk, sensitization in infancy is associated with asthma: 423 10-year follow-up of the PIAMA birth cohort. J Allergy Clin Immunol 2013; 132:14274248.

425 20. Just J, Saint-Pierre P, Gouvis-Echraghi R, Laoudi Y, Roufai L, Momas I et al. 426 Childhood allergic asthma is not a single phenotype. J Pediatr 2014; 164:815-20.

427 21. Lazic N, Roberts G, Custovic A, Belgrave D, Bishop CM, Winn J et al. Multiple 428 atopy phenotypes and their associations with asthma: similar findings from two birth 429 cohorts. Allergy 2013; 68:764-70.

430 22. Illi S, von Mutius E, Lau S, Nickel R, Gruber C, Niggemann B et al. The natural 431 course of atopic dermatitis from birth to age 7 years and the association with asthma. 432 J Allergy Clin Immunol 2004; 113:925-31. 